\title{
Physico-mechanical and morphological properties of rice husk- coconut husk fiber reinforced epoxy composites
}

\author{
Josephine Lai Chang Hui*, Fatin Fakhira Azman, Rubiyah Baini \\ Department of Chemical Engineering and Energy Sustainability, Faculty of Engineering, Universiti Malaysia Sarawak, Kota Samarahan, Sarawak
}

*Corresponding author:51768@siswa.unimas.my

\section{Article history}

Received 30 September 2019

Revised 21 January 2020

Accepted 10 May 2020

Published Online 16 August 2020

\begin{abstract}
In the recent years, many researches focus on "waste to wealth" concept, where agro-waste is converted into various valuable products especially on natural fiber polymeric composites. Selected fibers for this research were rice husk $(\mathrm{RH})$ and coconut husk $(\mathrm{CH})$. This research focused on the property enhancement of $\mathrm{RH}-\mathrm{CH}$ fiber reinforced epoxy composites and comparison $\mathrm{RH}$ reinforced epoxy composites, $\mathrm{CH}$ reinforced epoxy composites, and $\mathrm{RH}-\mathrm{CH}$ reinforced epoxy composites. $\mathrm{RH}$ $\mathrm{CH}$ reinforced epoxy composites were well-fabricated by mixing epoxy resin and different ratios of two types natural fibers via compression molding and stir casting methods. All the fabricated $\mathrm{RH}-\mathrm{CH}$ reinforced epoxy composites were characterized using Fourier Transform Infrared Spectroscopy (FTIR), Scanning Electron Microscopy (SEM), Vickers Hardness Test (VHT), and tensile test (TT). FTIR results showed that $10 \mathrm{wt} \% \mathrm{RH}-\mathrm{CH}$ reinforced epoxy composites created the strongest covalent bonding between cellulose inside $\mathrm{RH}-\mathrm{CH}$ fiber and epoxide group compared to $\mathrm{RH}$ reinforced epoxy composites and $\mathrm{CH}$ reinforced epoxy composites. The combination of $\mathrm{RH}$ and $\mathrm{CH}$ fiber with the introduction of epoxy resin reduced the hydroxyl groups compared to either $\mathrm{RH}$ or $\mathrm{CH}$ fiber composites, respectively. This proved that mixture of $\mathrm{RH}$ and $\mathrm{CH}$ with epoxy matrix improved the properties of pure $\mathrm{RH}$ and $\mathrm{CH}$ and thus, better composites were fabricated. SEM images of $10 \mathrm{wt} \% \mathrm{RH}-\mathrm{CH}$ reinforced epoxy composites showed better dispersion of $\mathrm{RH}-\mathrm{CH}$ fiber within polymer matrix compared to $\mathrm{RH}$ reinforced epoxy composites and $\mathrm{CH}$ reinforced epoxy composites under the magnification of 2000 . Both $\mathrm{RH}$ reinforced epoxy composites and $\mathrm{CH}$ reinforced epoxy composites showed porosity within the matrix. VHT showed that $10 \mathrm{wt} \% \mathrm{RH}-\mathrm{CH}$ reinforced epoxy composites showed the smallest indentation value compared to $\mathrm{RH}$ reinforced epoxy composites and $\mathrm{CH}$ reinforced epoxy composites due to the highest interfacial adhesion between matrix and filler, which was proven by the SEM images. Tensile test of $10 \mathrm{wt} \% \mathrm{RH}-\mathrm{CH}$ reinforced epoxy composites showed the highest tensile modulus with value of 2.6MPa. $\mathrm{RH}-\mathrm{CH}$ reinforced epoxy composites showed higher tensile strength and modulus compared to $\mathrm{RH}$ and $\mathrm{CH}$ reinforced epoxy composites. Overall, it could be concluded that $10 \mathrm{wt} \% \mathrm{RH}-$ $\mathrm{CH}$ reinforced epoxy composites performed the best in terms of physical, mechanical, and morphological perspective than $\mathrm{RH}$ reinforced epoxy composites and $\mathrm{CH}$ reinforced epoxy composites. This proved that $\mathrm{RH}$ and $\mathrm{CH}$ could be well-introduced as reinforcing filler in epoxy matrix to fabricate better composites for structural application.
\end{abstract}

Keywords: rice husk, coconut shell, stir casting method, FTIR, SEM, VHT, TT

\section{INTRODUCTION}

Renewable energy such as biomass is currently not adequately utilized to replace the non-renewable sources [1]. The depletion of natural resources results on the urgency to exploit clean renewable energy to reduce the bad impacts on the environment. The advantages of renewable energy are numerous such as maintainable, clean, and do not pollute the environment [2]. One of the promising sources of renewable energy is biomass as it can be found extensively in both developing and developed countries. In general, biomass can be defined as the organic matter derived from living organisms such as human, plant, and animal [3]. Agriculture wastes from harvesting or processing are biomass that can be transformed into different vast array of valuable products. This waste should be utilized due to its low cost, reproducible, decomposable, easy to be accessed from various sources, and environmental-friendly [4]. Agriculture waste can be found abundantly in Asia including rice producing industry. One of biomass resources, rice plantations, has recently developed consecutively under high demand as essential food resources in several countries, especially across Asia [5]. It has been reported that $90 \%$ of the world's rice is consumed and produced in Asia where China and India are the largest Asian producers [6]. The research stated that half of the world production and consumption in 2011 dominated by China and India. From this large-scale production, the waste from rice plantation consisting of rice straw and husk is about 1,370,000 million t per year [5].

Rice husk (RH) is a by-product from rice industry which is produced during the earliest stage of rice milling and is commonly burnt or dumped as waste [7]. The burning of RH results in air pollution and damage to land and surrounding area where it is discarded. Extensive 
research has been carried out on application of RH to make full use of agro-waste from becoming a great threat to the environment [8]. The past researchers revealed that RH can be utilized and converted into energy such as fuel source, organic fertilizer, building materials, and used to remove toxic metals from wastewater [9].

The characteristics of RH are suitable to create a new composite material for construction applications without involving burning and grinding [10]. Researches conducted today are driven by the environmental concern with the massive production of agro-waste. Instead of being disposed, the agro-waste is utilized and converted into new beneficial material. Apart from RH, coconut shell (CS) is one of biomass that can be utilized and converted into new energy and product. Coconut plantation can be found abundantly in Malaysia [11] However, coconut industry does not contribute much to the overall economy of Malaysia. Coconut shell is a potential agro-waste for the productions of new composites due to their mechanical properties and high strength [12]. High strength coconut composites can be used in the wide range of applications such as materials for construction, furniture and other household appliances. Using coconut is advantageous as it is vastly planted in tropical countries like Malaysia, Thailand, Indonesia, and Sri Lanka where it thrives due to the climate.

\section{EXPERIMENTAL}

\section{Preparation of rice husk $(\mathrm{RH})$}

Raw RH as shown in Fig. 1 was ground by using Panasonic MXAC400 grinder to obtain smaller form of RH as shown in Fig. 2 to increase the surface roughness and contact area of the RH. Ground RH was then sieved by using $1 \mu \mathrm{m}$ stainless steel lab wire mesh test sieve, before it is stored in desiccator to avoid contamination.

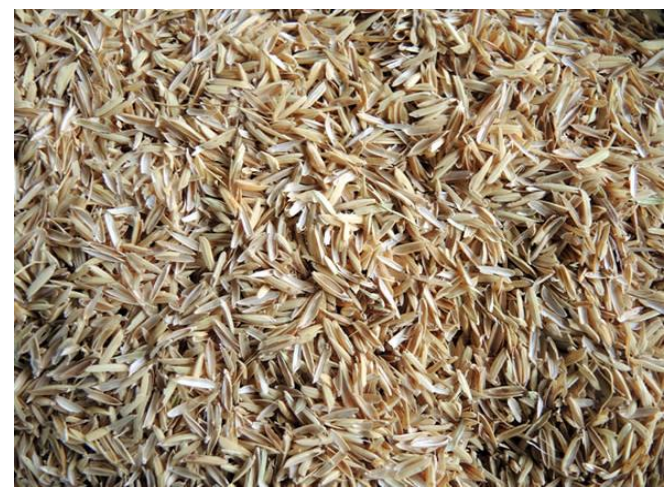

Fig. 1 Raw RH.

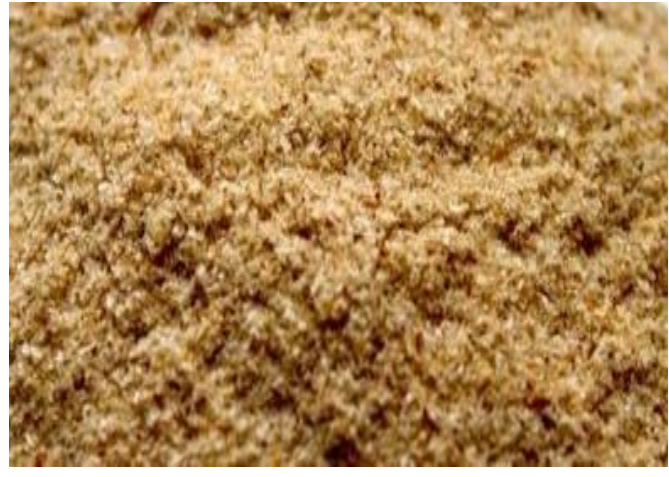

Fig. 2 Ground $\mathrm{RH}$.

\section{Preparation of coconut husk $(\mathrm{CH})$}

Raw $\mathrm{CH}$ was collected from coconut factory as shown in Fig. 3. The outer and inner surface of the $\mathrm{CH}$ collected was scrubbed and washed thoroughly with tap water to remove the impurities as shown in Fig. 4. The coir fiber surrounded the $\mathrm{CH}$ completely removed. The $\mathrm{CH}$ was then dried in sunlight for 2 days to remove the moisture content and dried inside the oven for 8 hours to ensure the $\mathrm{CH}$ was perfectly dried. Dried $\mathrm{CH}$ was crushed into small pieces by using hammer and grinded using Panasonic MX-AC400 grinder to obtain smaller form of $\mathrm{CH}$ to increase the surface roughness and contact area of the $\mathrm{CH}$ as shown in Fig. 5. Ground $\mathrm{CH}$ was then sieved by using $1 \mu \mathrm{m}$ stainless steel lab wire mesh test sieve as shown in Fig. 6. Sieved $\mathrm{CH}$ was stored in desiccator to avoid any contamination on the $\mathrm{CH}$.

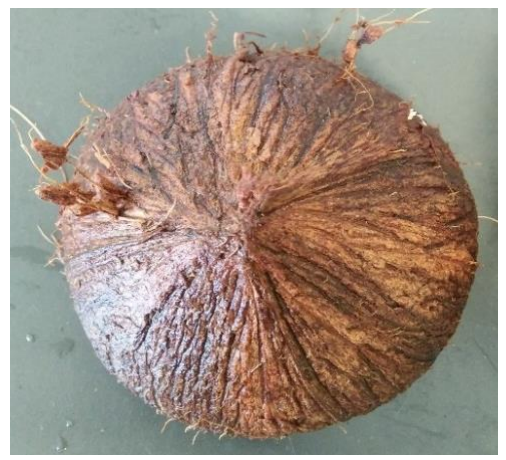

Fig. 3 Raw $\mathrm{CH}$.

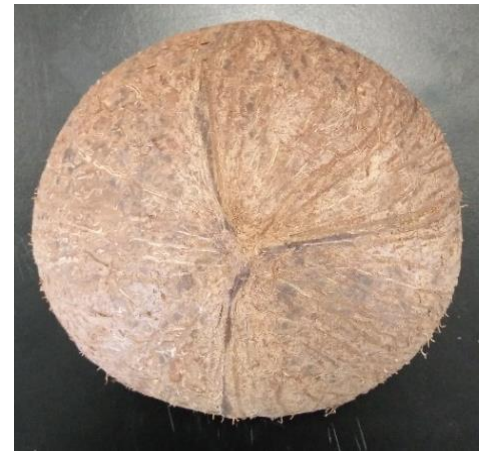

Fig. 4 Clean and dried $\mathrm{CH}$.

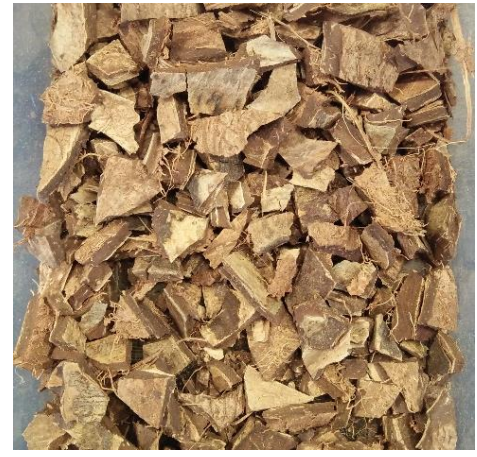

Fig. 5 Crushed $\mathrm{CH}$.

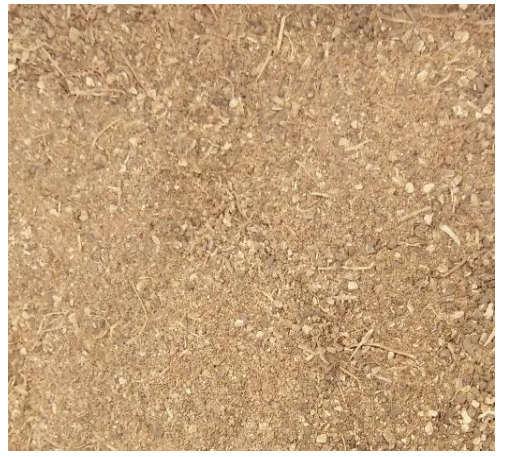

Fig. 6 Ground $\mathrm{CH}$ powder.

\section{Preparation of epoxy}

Epoxy resin and hardener were mixed at ratio of 2:1 where a mixture $10 \mathrm{ml}$ of epoxy resin and $5 \mathrm{ml}$ of hardener was stirred slowly to avoid the formation of air bubble. The same process was repeated by 
using different ratios of epoxy. Preparation of epoxy must be done right before the preparation of samples to avoid the mixture from hardened.

Preparation of $\mathrm{RH}$ reinforced epoxy composite, $\mathrm{CH}$ reinforced epoxy composite, and $\mathrm{RH}-\mathrm{CH}$ reinforced epoxy composite using Solution Casting Method

Dried fillers were added into a mixture of epoxy resin and hardener according to desired ratios. The mixture of epoxy and fillers were then mixed thoroughly before poured into $2 \mathrm{~mm}$ thickness dog bone shape stainless steel mold as shown in Fig. 7. GOTECH Hydraulic Molding Test Press machine and stir casting method were used for all the samples prepared as shown in Table 1 .

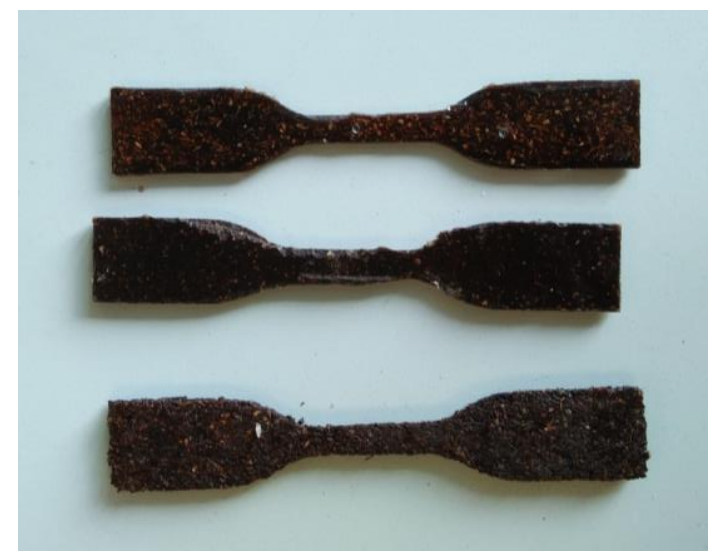

Fig. 7 Dog bone-shaped composites.

Characterizations of $\mathrm{RH}$ reinforced epoxy composite, $\mathrm{CH}$ reinforced epoxy composite and $\mathrm{RH}-\mathrm{CH}$ reinforced epoxy composite

$\mathrm{RH}$ reinforced epoxy composite, $\mathrm{CH}$ reinforced epoxy composite, and $\mathrm{RH}-\mathrm{CH}$ reinforced epoxy composite were characterized using Fourier Transform Infrared (FTIR) Spectroscopy, Scanning Electron Microscopy (SEM), Vickers Hardness Test (VHT), and Tensile Test (TT).

\section{Fourier transform infrared (FTIR) spectroscopy}

Fourier Transform Infrared Spectrophotometer (MODEL IRAFFINITY-1 CE SHIMADZU, Fig. 8) was used to obtain information on the composition properties and to identify any chemical bonding of RH-CH reinforced epoxy composite. These samples were tested in the wavelength spectra within a range of 4000 to $400 \mathrm{~cm}^{-1}$ with $4 \mathrm{~cm}^{-1}$ resolutions and 10 numbers of scan.

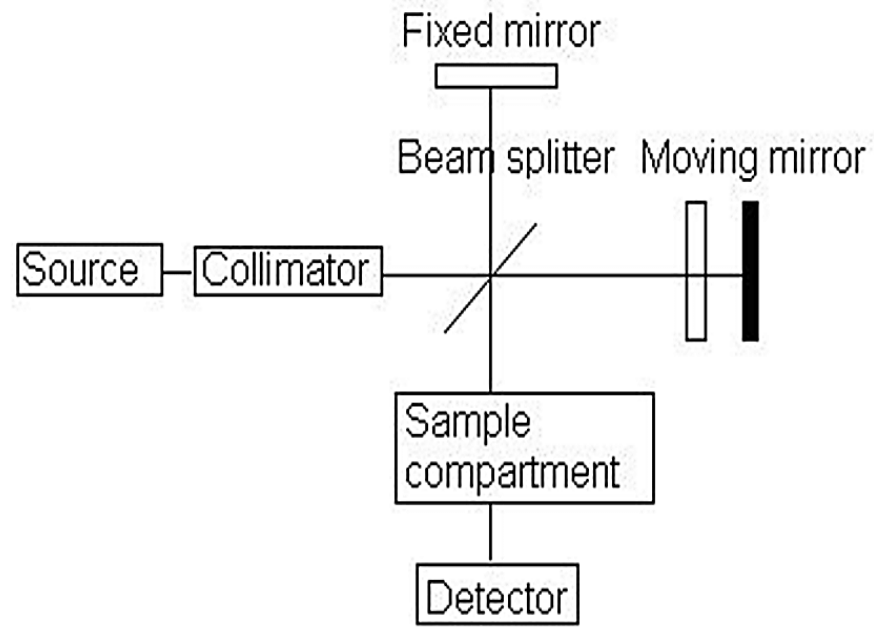

Fig. 8 Operations Schematic of Fourier Transform IR (FTIR) spectrometer [13].

\section{Scanning electron microscopy (SEM)}

Scanning Electron Microscopy (SEM) model TM3030 by HITACHI (Fig. 9) was used in this study to obtain information on the surface morphology of RH-CH reinforced epoxy composite. The proposed voltage for this test was $15 \mathrm{kV}$ to study the crystalline phase of samples. The samples were coated using gold dust before analyzed as shown in Fig. 10. Coated samples placed on carbon tape before placing on the top of the specimen of SEM machine was shown in Fig. 11. The samples were analyzed under 2000 magnification.

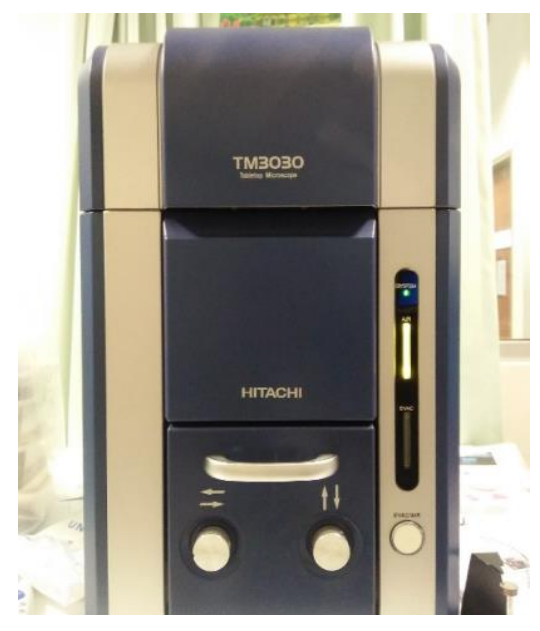

Fig. 9 SEM machine.

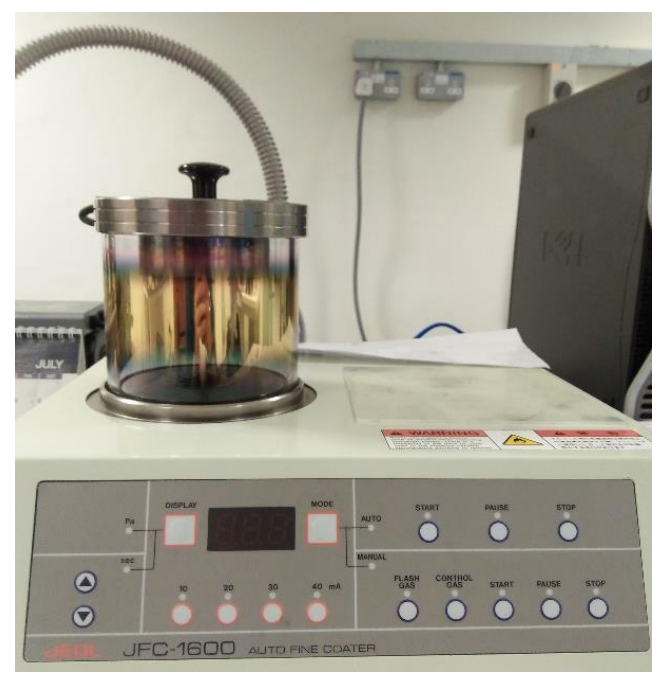

Fig. 10 Sample coating by using Gold Dust.

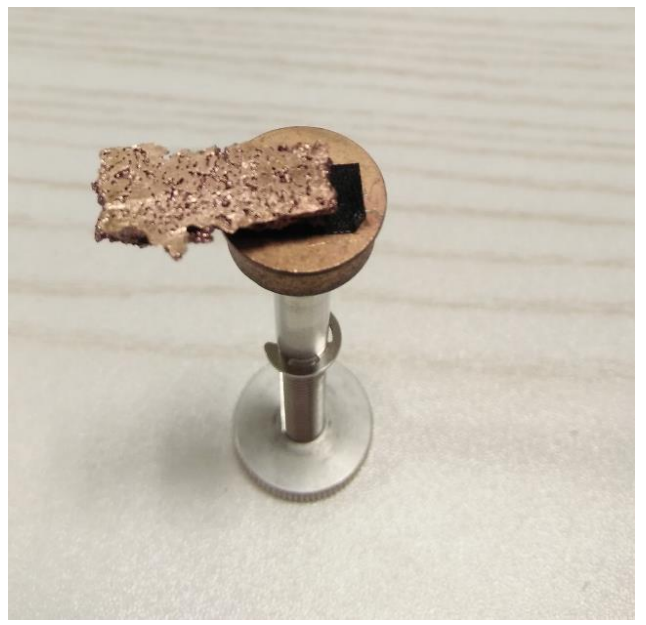

Fig. 11 Coated sample on carbon tape. 


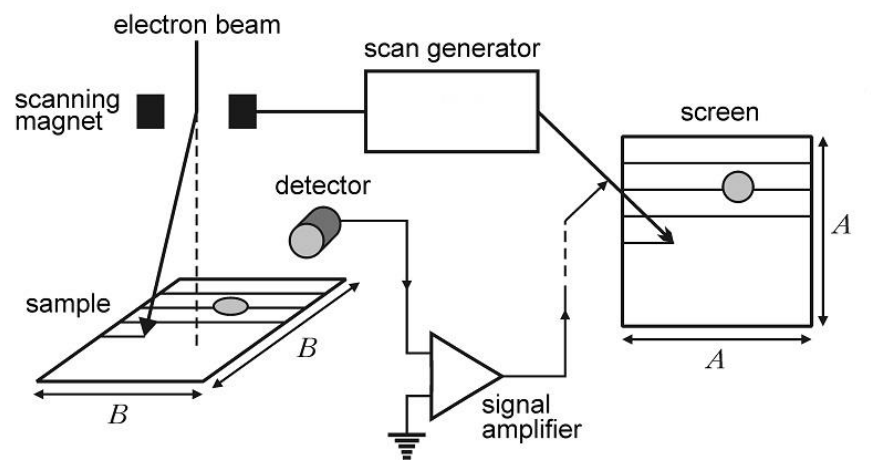

Fig. 12 Operation schematic of Scanning Electron Microscopy [14].

\section{Vickers hardness test (VHT)}

Vickers Hardness Test (VHT) by HITACHI (Fig. 12) was used in this study to investigate information on the surface morphology of $\mathrm{RH}-$ $\mathrm{CH}$ reinforced epoxy composite. The composites undergo indenting process with diamond indenter for 10 seconds as shown in Fig. 13. Five readings were taken for each sample to find the average readings of Vickers Hardness (HV). The force used to indent the surface of the sample was $9.807 \mathrm{~N}$ which is the standard force to test epoxy composites. The value of $\mathrm{HV}$ is converted to MPa by multiplying $\mathrm{HV}$ value by $9.807 \mathrm{~N}$.

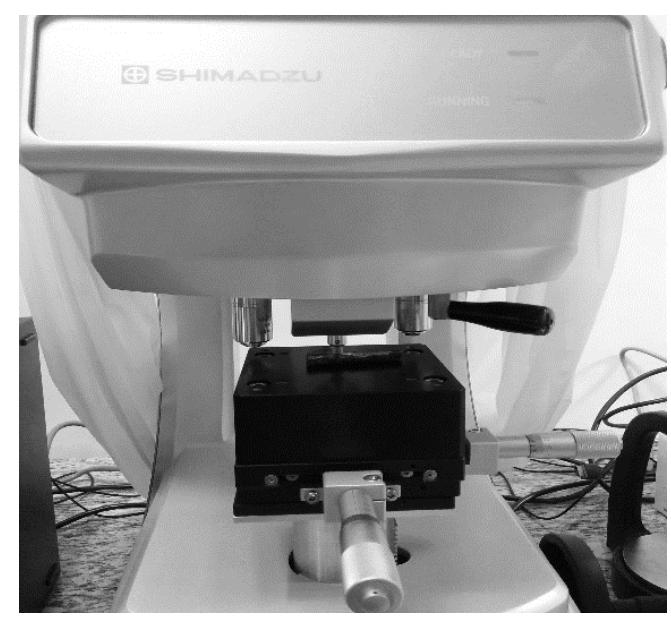

Fig. 12 Vickers Hardness Machine.

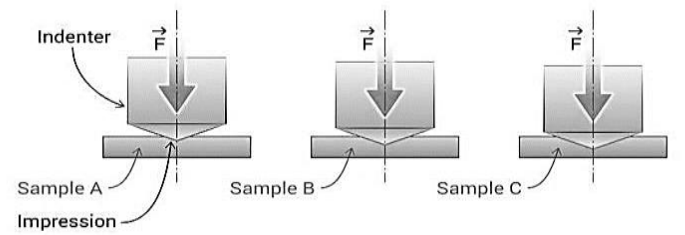

Measurement of impression diagonals

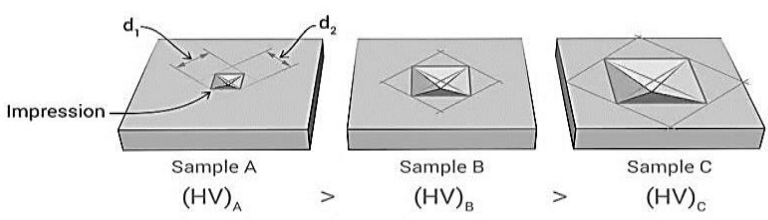

Fig. 13 VHT Process Diagram [15].

\section{Tensile test (TT)}

A tensile test (TT) is a basic mechanical test in which a carefully prepared specimen is loaded very controlled while measuring the load applied and the elongation of the specimen over a certain distance. This test is commonly used to determine the elasticity, elastic limit, elongation, proportional limit, tensile strength, yield point, and other properties of tensile. The traction properties indicate how the material will react to the stressed forces. In this study, TT was carried out using SHIMADZU AG-IS 300kN tensile machine as shown in Fig. 14. The variation of tensile modulus was analyzed at a crosshead speed of $5 \mathrm{~mm} / \mathrm{min}$.

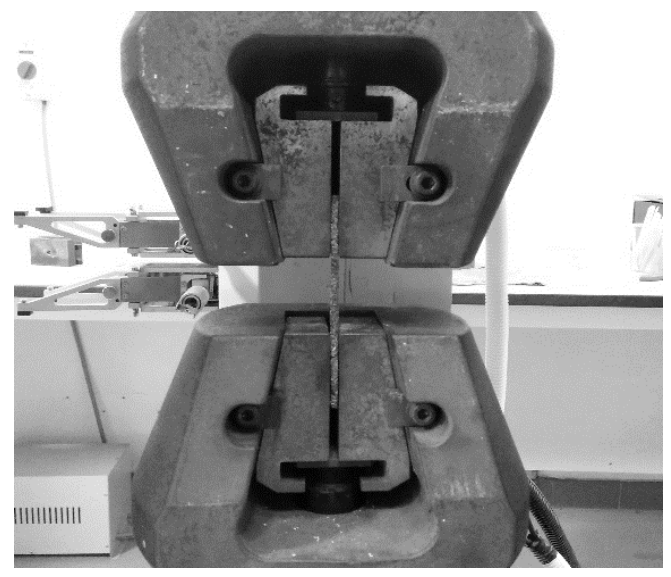

Fig. 12 Tensile Test Machine.

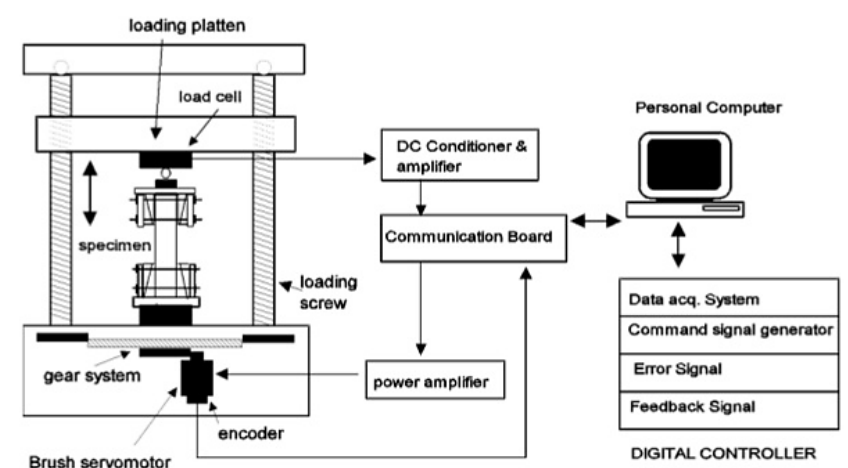

Fig. 16 Schematic Diagram of Tensile Test Process [16]

\section{RESULTS AND DISCUSSION}

\section{Fourier transform infrared (FTIR) spectroscopy}

Fourier transform infrared (FTIR) spectroscopy was performed based on the suggested ratios as shown in Table 1. FTIR spectra of $10 \mathrm{wt} \% \mathrm{RH}$ reinforced epoxy composite, $10 \mathrm{wt} \% \mathrm{CH}$ reinforced epoxy composite and 10wt\% RH-CH reinforced epoxy composites was clearly shown in Fig. 16, 17, and 18, respectively. 10wt\% of RH reinforced epoxy composite showed significant peaks at $3395 \mathrm{~cm}^{-1}$ and $3278 \mathrm{~cm}^{-1}$ which was related to $\mathrm{O}-\mathrm{H}$ transmittance as shown in Fig. 16. Besides, $\mathrm{C}-\mathrm{H}$ covalent bond was clearly shown in $10 \mathrm{wt} \% \mathrm{RH}$ reinforced epoxy composite with peak values of $2970 \mathrm{~cm}^{-1}, 2901 \mathrm{~cm}^{-1}$ and $2726 \mathrm{~cm}^{-1}$. Fig. 17 shows that $10 \mathrm{wt} \% \mathrm{CH}$ reinforced epoxy composite had no significant peak within $3600-3200 \mathrm{~cm}^{-1}$. This composite also showed strong $\mathrm{C}-\mathrm{H}$ covalent bond within the composite at peaks value of $2974 \mathrm{~cm}^{-1}$ and $2810 \mathrm{~cm}^{-1}$. Fig. 18 demonstrated that $10 \mathrm{wt} \%$ RH-CH reinforced epoxy composites had significant improvement at hydroxyl peak by combining $\mathrm{RH}$ and $\mathrm{CH}$. Besides, $\mathrm{C}$ $\mathrm{H}$ covalent bonding was clearly shown in $10 \mathrm{wt} \% \mathrm{RH}-\mathrm{CH}$ reinforced epoxy composites with peak values of $2942 \mathrm{~cm}^{-1}$ and $2892 \mathrm{~cm}^{-1}$. A symmetrical peak observed at $1506.47 \mathrm{~cm}^{-1}$ for $10 \mathrm{wt} \% \mathrm{RH}-\mathrm{CH}$ reinforced epoxy composites which showed $\mathrm{C}-\mathrm{OH}$ stretching bonds that strengthened the composites and reducing hydroxyl groups by attaching to carbon groups [17]. From FTIR results, 10wt\% RH-CH reinforced epoxy composites created strong covalent bonding between cellulose inside $\mathrm{RH}-\mathrm{CH}$ fiber and epoxide group compared to $15 \mathrm{wt} \%$ and $20 \mathrm{wt} \% \mathrm{RH}-\mathrm{CH}$ reinforced epoxy composites. Significant reduction in hydroxyl groups were shown in 10wt $\%$ RH-CH reinforced epoxy composites due to the combination of $\mathrm{RH}$ and $\mathrm{CH}$ fiber with the introduction of epoxy resin. This proved that mixture of $\mathrm{RH}$ and $\mathrm{CH}$ 
with epoxy matrix improved the properties of pure $\mathrm{RH}$ and $\mathrm{CH}$ and thus, better composites were fabricated.

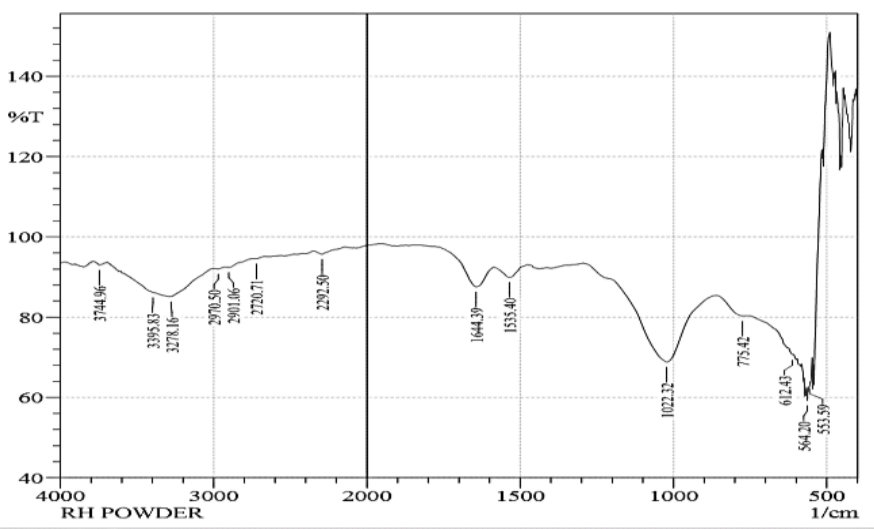

Fig. $16 \mathrm{FTIR}$ analysis of $10 \mathrm{wt} \% \mathrm{RH}$ reinforced epoxy composites.

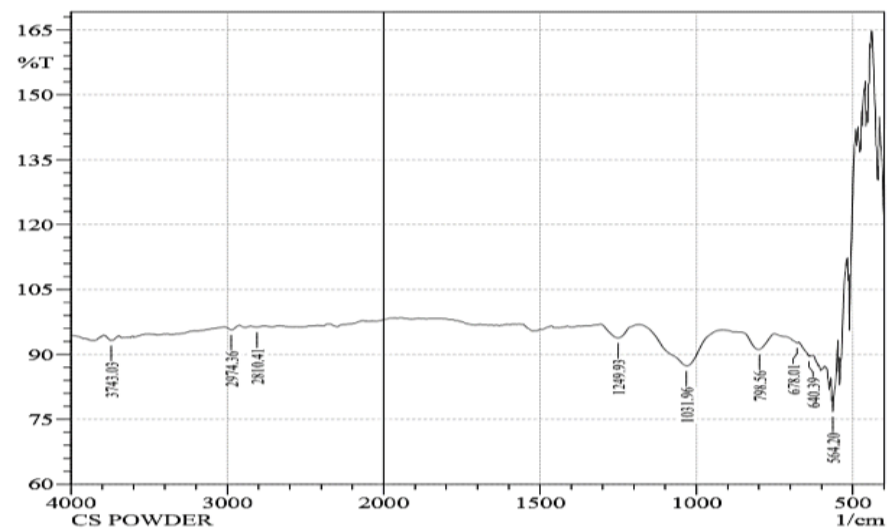

Fig. 17 FTIR analysis of $10 w t \%$ RH reinforced epoxy composites.

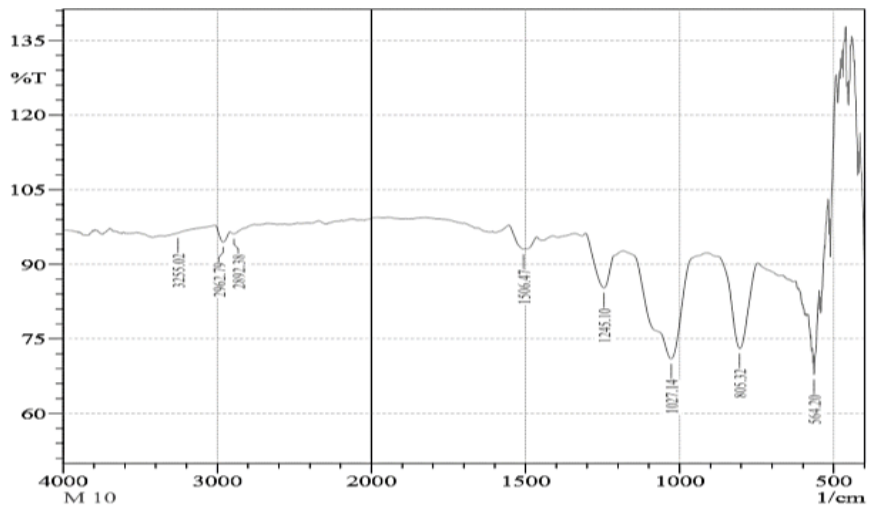

Fig. $18 \mathrm{FTIR}$ analysis of $10 \mathrm{wt} \% \mathrm{RH}$ reinforced epoxy composites.

\section{Scanning electron microscopy (SEM)}

The fracture surface morphology shows the phase information that reflects the mechanical properties of composites under different conditions. The tensile fracture surface morphologies of $10 \mathrm{wt} \% \mathrm{RH}$ reinforced epoxy composite, $10 \mathrm{wt} \% \mathrm{CH}$ reinforced epoxy composite and $10 \mathrm{wt} \% \mathrm{RH}-\mathrm{CH}$ reinforced epoxy composites under magnification of 2000 are shown in Fig. 19, Fig. 20, and Fig. 21, respectively. 10wt\% $\mathrm{RH}$ reinforced epoxy composite showed high dispersion of the $\mathrm{RH}$ into the epoxy as shown in Fig. 4.12. This results in better interfacial adhesion between the filler and matrix. However, few pores were observed on the surface of $10 \mathrm{wt} \% \mathrm{RH}$ reinforced epoxy composite was probably due to air bubble formation during the preparation of epoxy [18]. SEM image of $10 \mathrm{wt} \% \mathrm{CH}$ reinforced epoxy composite showed cracking lines as well as micro-voids of the fiber in the epoxy matrix. These features suggested weak interfacial bonding between the filler and the matrix. Fig. 21 shows that $10 w t \%$ RH-CH reinforced epoxy composites had the smoothest surfaces with no voids or pores detected on the surface itself [19]. This proved the strong covalent bonding and reduction of hydroxyl groups by combining two types of husks with epoxy to form better composites.

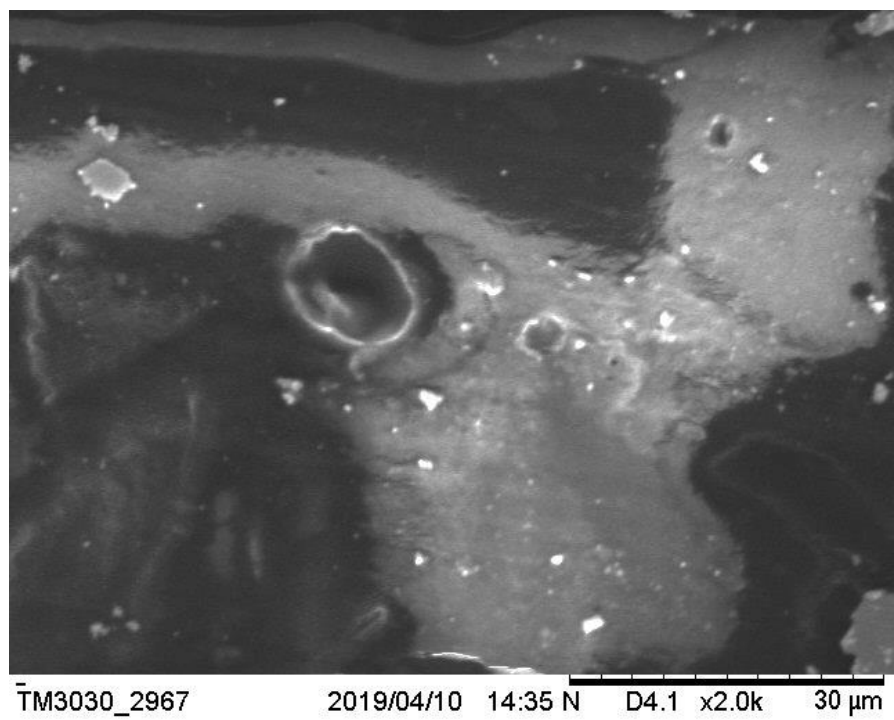

Fig. 19 SEM of $10 w t \% \mathrm{RH}$ reinforced epoxy composites.

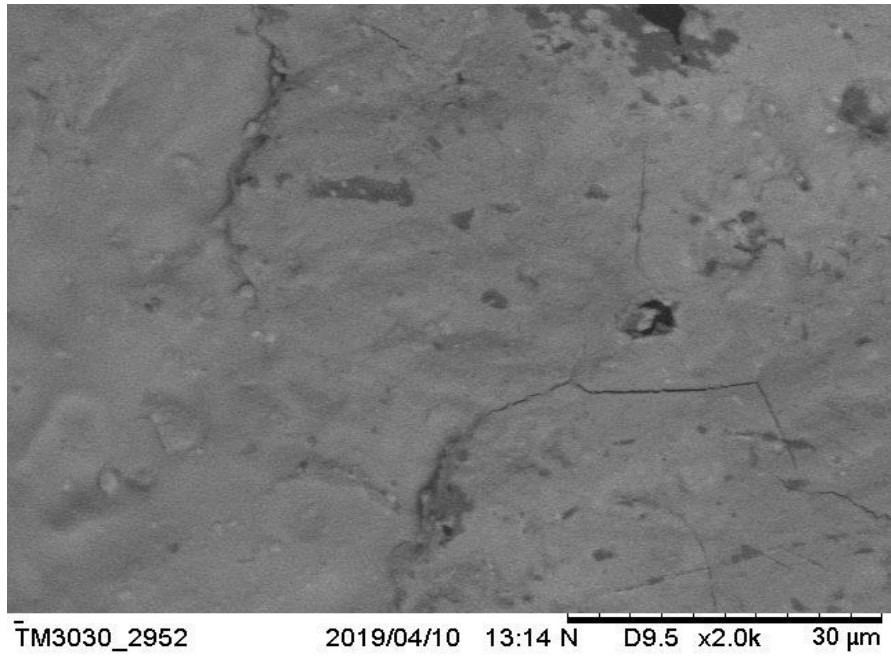

Fig. 20 SEM of $10 w t \%$ RH reinforced epoxy composites.

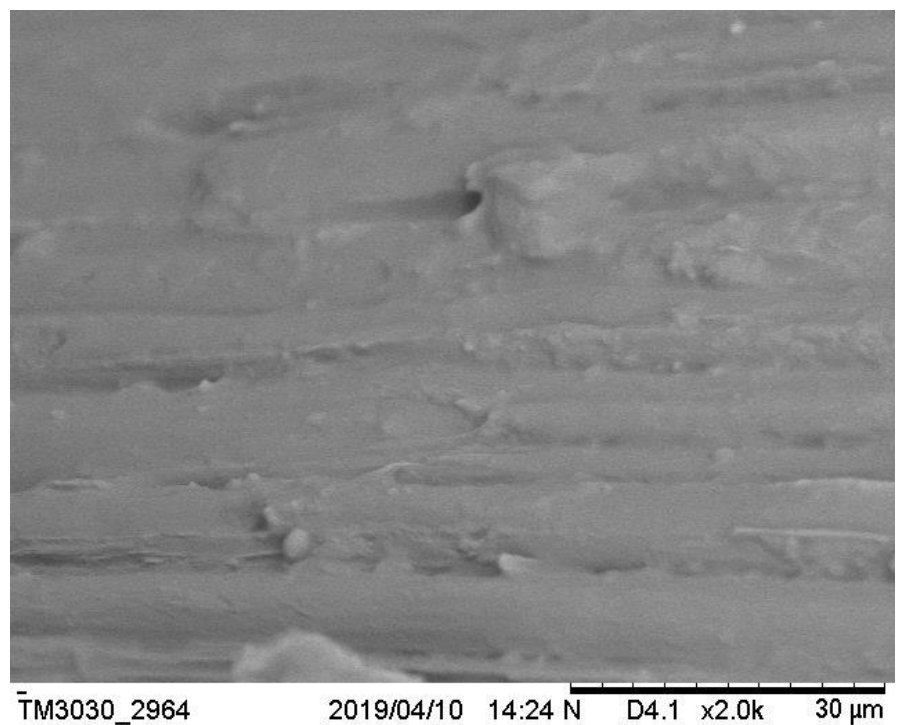

Fig. 21 SEM of $10 w t \%$ RH reinforced epoxy composites. 


\section{Vickers hardness test (VHT)}

Fig. 22, Fig. 23, and Fig. 24 show the indentation of $10 \mathrm{wt} \%$ RH reinforced epoxy composite, $10 \mathrm{wt} \% \mathrm{CH}$ reinforced epoxy composite and $10 \mathrm{wt} \% \mathrm{RH}-\mathrm{CH}$ reinforced epoxy composites, respectively. 10wt\% $\mathrm{RH}-\mathrm{CH}$ reinforced epoxy composites showed the smallest indentation compared to $10 \mathrm{wt} \% \mathrm{RH}$ reinforced epoxy composite and $10 \mathrm{wt} \% \mathrm{CH}$ reinforced epoxy composite. The highest interfacial adhesion between the filler and matrix as shown in Fig. 21 explained that 10wt\% RH-CH reinforced epoxy composites had the smallest dent and highest average force applied on the surface. 10wt\% RH reinforced epoxy composite showed the biggest dent and the lowest average force applied during indentation compared other composites due to high amount of porosity which resulted in weak interfacial bonding between $\mathrm{RH}$ fillers and epoxy [20]. 10wt\% CH reinforced epoxy composite showed smaller dent compared to $10 \mathrm{wt} \% \mathrm{RH}$ reinforced epoxy composites as it had higher interfacial adhesion between filler and matrix [21]. Overall, 10wt\% RH-CH reinforced epoxy composites was having the best VHT by having the smallest dent among all the composites.

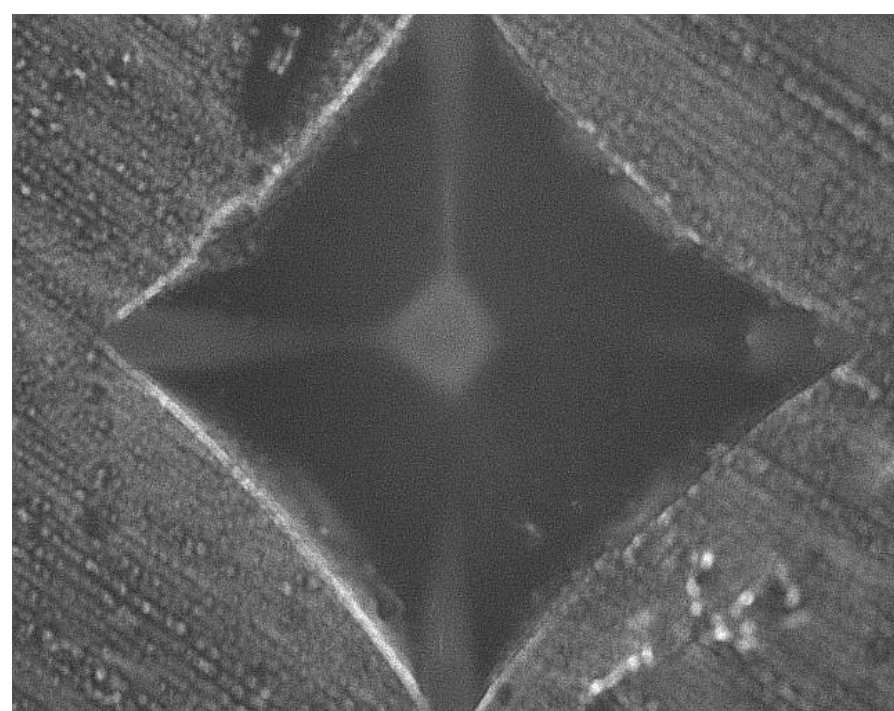

Fig. 22 Indentation on 10wt\% $\mathrm{RH}$ reinforced epoxy composites.

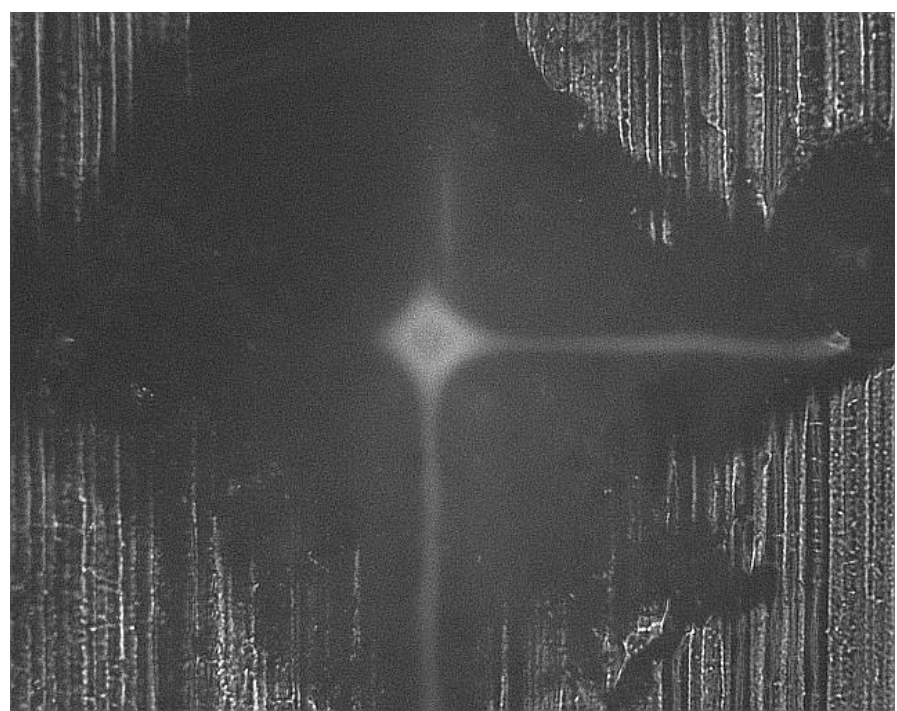

Fig. 23 Indentation on 10wt\% $\mathrm{RH}$ reinforced epoxy composites.

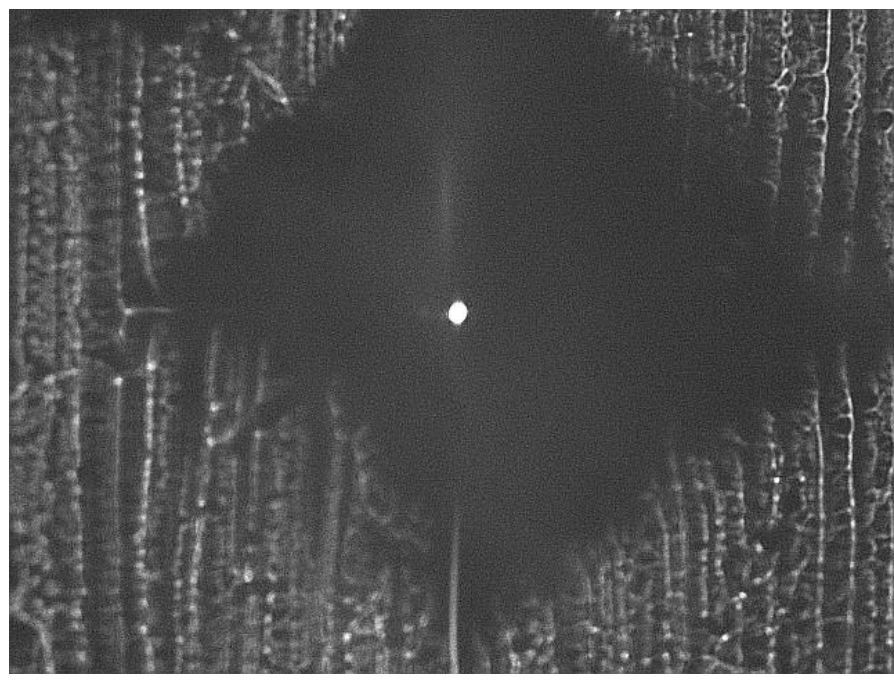

Fig. 24 Indentation on 10wt\% RH reinforced epoxy composites.

\section{Tensile test}

Fig. 25, Fig. 26, and Fig. 27 demonstrate the tensile strength curve (stress versus strain) of 10wt $\%$ RH reinforced epoxy composite, $10 \mathrm{wt} \%$ $\mathrm{CH}$ reinforced epoxy composite and $10 \mathrm{wt} \% \mathrm{RH}-\mathrm{CH}$ reinforced epoxy composites respectively. 10wt\% $\mathrm{RH}-\mathrm{CH}$ reinforced epoxy composites had the highest tensile strength compared to $10 \mathrm{wt} \% \mathrm{RH}$ reinforced epoxy composite and $10 \mathrm{wt} \% \mathrm{CH}$ reinforced epoxy composite due to the excellent interfacial adhesion between RH-CH and epoxy. Fig. 25 shows that $10 \mathrm{wt} \% \mathrm{RH}$ reinforced epoxy composite showed the tensile the elasticity only managed to handle stress up to $0.4 \mathrm{MPa}$ where $10 \mathrm{wt} \%$ $\mathrm{RH}$ reinforced epoxy composite managed to handle stress up to $0.6 \mathrm{MPa}$. $10 \mathrm{wt} \% \mathrm{RH}-\mathrm{CH}$ reinforced epoxy composites showed the highest stress level among all the composites with value up to $2.6 \mathrm{MPa}$. This proved that $10 \mathrm{wt} \% \mathrm{RH}$ reinforced epoxy composite had the lowest tensile strength and modulus due to poor interaction between $\mathrm{RH}$ and epoxy as observed in SEM and VHT. In addition, 10wt\% RH reinforced epoxy composite is also brittle due to lower strain compared to other composites [22]. This showed that 10wt\% RH reinforced epoxy composite had the weakest interaction between filler and matrix as it has the lowest tensile strength and modulus. Tensile test of 10wt\% RH$\mathrm{CH}$ reinforced epoxy composites showed the highest tensile modulus with value of $2.6 \mathrm{MPa}$. Overall, 10wt\% $\mathrm{RH}-\mathrm{CH}$ reinforced epoxy composites showed higher tensile strength and modulus compared to $\mathrm{RH}$ and $\mathrm{CH}$ reinforced epoxy composites.

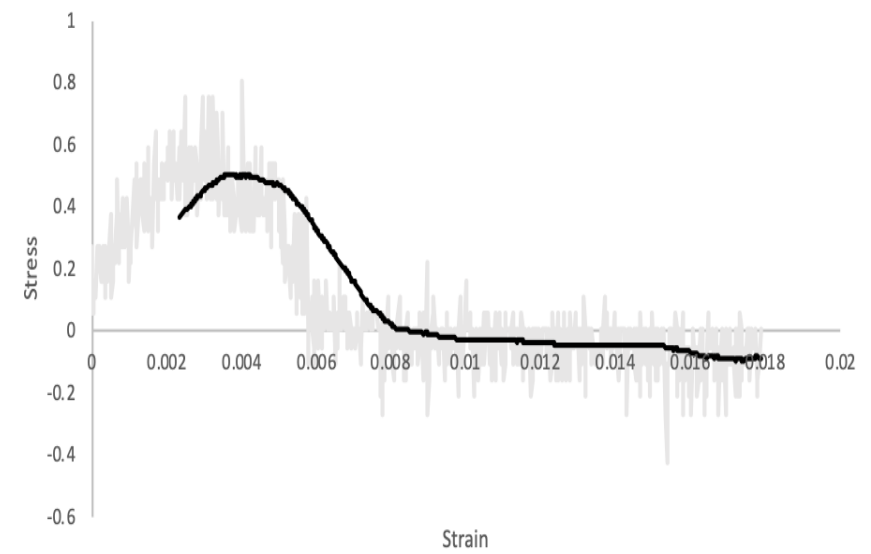

Fig. 25 Stress Versus Strain Graph of 10wt\% RH reinforced epoxy composites. 


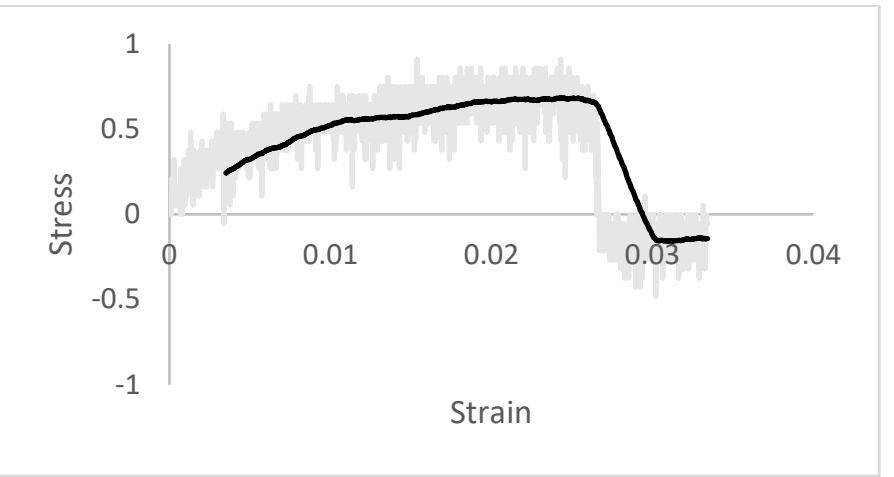

Fig. 26 Stress Versus Strain Graph of 10wt\% CH reinforced epoxy composites.

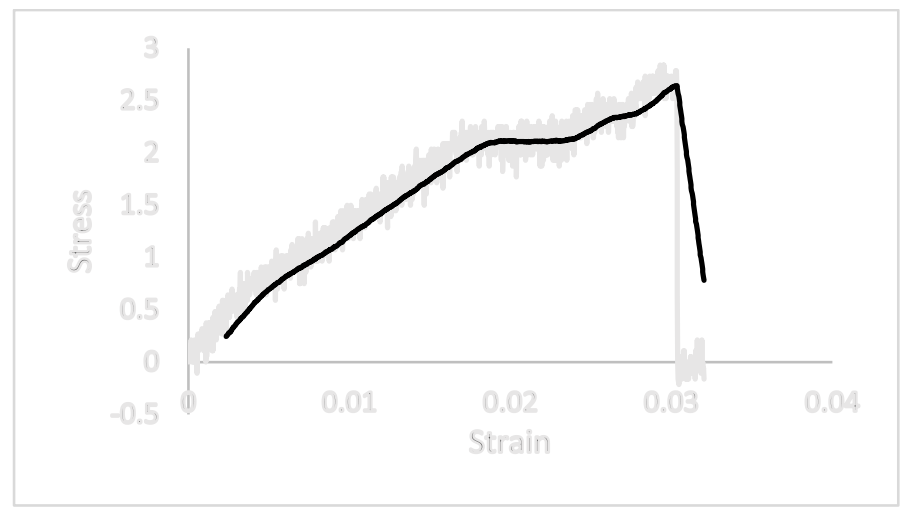

Fig. 27 Stress versus Strain Graph of 10wt\% RH-CH reinforced epoxy composites.

\section{CONCLUSION}

The present study reveals that $\mathrm{RH}$ and $\mathrm{CH}$ could be successfully reinforced with epoxy for better composites fabrication. Overall, $10 \mathrm{wt} \% \mathrm{RH}-\mathrm{CH}$ reinforced epoxy composites has been determined to be the best type of composite compared to RH and $\mathrm{CH}$ composites. FTIR analysis showed that 10wt\% RH-CH reinforced epoxy composites had many interactions between the cellulose inside $\mathrm{RH}-\mathrm{CH}$ fiber and epoxide group inside the epoxy. 10wt $\%$ RH-CH reinforced epoxy composites was the best composites fabricated with better morphology by showing better dispersion of fiber in the epoxy matrix compared to $10 \mathrm{wt} \% \mathrm{RH}$ reinforced epoxy composites and 10wt\% $\mathrm{CH}$ reinforced epoxy composites. In addition, 10wt\% $\mathrm{RH}-\mathrm{CH}$ reinforced epoxy composites showed the best tensile strength and modulus as well as the smallest dent. It can be concluded that $10 \mathrm{wt} \% \mathrm{RH}-\mathrm{CH}$ reinforced epoxy composites had better physical, mechanical, and morphological properties compared to $10 \mathrm{wt} \% \mathrm{RH}$ reinforced epoxy composites and $10 \mathrm{wt} \% \mathrm{CH}$ reinforced epoxy composites.

\section{ACKNOWLEDGEMENT}

The authors would like to thank Universiti Malaysia Sarawak for the Grant (F02/TOC/1748/2018).

\section{REFERENCES}

[1] J. G. Cedeño-Laurent, Ann. Rev. Pub Health 39 (2018) 291.

[2] E. Azwar, W. A. W. Mahari, J. H. Chuah, D. V. N. Vo, N. L. Ma, W. H. Lam, S. S. Lam, Int. J. Hydrogen Energ, 43 (2018) 20811.

[3] J. Sánchez, M. D. Curt, N. Robert, J. Fernández, Biomass Resources: The Role of Bioenergy in the Bioeconomy, Academic Press, United States, 2019, p. 25.

[4] Y. Dai, Q. Sun, W. Wang, L. Lu, M. Liu, J. Li, S. Yang, Y. Sun, K. Zhang, W. Zheng, Z. Hu, Y. Yang, Y. Gao, Y. Chen, X. Zhang, F. Gai, Y. Zhang, Chemosphere 211 (2018) 235.

[5] A. Darmawan, A. C. Fitrianto, M. Aziz, K. Tokimatsu, Appl. Energy 220 (2018) 672.

[6] T. Ramziath, M. John, M. Glob, Food Secr. 5 (2015) 50.

[7] R. M. Mohamed, I. A. Mkhalid, M. A. Bakarat, Arab. J. Chem. 8 (2015) 48.

[8] B. Mistry, Int. J. Eng. Sci. 6 (2016) 2677.

[9] P. N. Babaso, H. Sharanagouda, Int. J. Curr. Microbiol. Appl. Sci. 6 (2017) 1144.

[10] J. António, A. Tadeu, B. Marques, J. A. Almeida, V. Pinto, Constr. Build. Mater. 176 (2018) 432.

[11] S. A. Sulaiman, R. Roslan, M. Inayat, M. Y. Naz, J. Energ. Inst. 91 (2018) 779 .

[12] Z. Salleh, M. M. slam, M. Y. M. Yusop, M. M. A. M. Idrus, APCBEE Procedia, 9 (2014) 92.

[13] M. Abi, S. Chayo, Suwarno, Energ. 11 (2018) 364.

[14] J. Goldstein, Ch. Lyman, D. E. Newbury, D. C. Joy, P. Echlin, E. Lifshin, L. Sawyer, J. R. Micheal, Eds.), The SEM and Its Mode of Operation, Springer, Germany, 2003, p. 21.

[15] T. W. W. Lestari, A. Wijonarko, W. Murdita, Suputa, J. Perlindungan Tanaman Indonesia 21 (2017) 38

[16] D. T. Read, Tensile Testing of Thin Films: Techniques and Results, National Institute of Standard and Technology, 1997, p. 13.

[17] F. Matossi, J. Chem. Phys. 17 (1949) 679.

[18] S. Sankar, S. K. Sharma, N. Kaur, B. Lee, D. Y. Kim, S. Lee, H. Jung, Ceram. Int. 42 (2016) 4875.

[19] J. Ka'zmierczak, S. Biniak, A. Swiatkowski, H. Radeke, J. Chem. Soc. Faraday Transac. 87 (1991) 3557.

[20] S. Biniak, G. Szymański, J. Siedlewski, A. Świạ Tkowski, Carbon, 35 (1997) 1799

[21] V. Sricharoenchaikul, C. Pechyen, D. Aht-Ong, D. Atong, Waste Energ. Fuel. 22 (2008) 31.

[22] M. Lesaoana, R. P. V. Mlaba, F. M. Mtunzi, P. Edijike, V. E. Pakade, South Afri.J. Chem. Eng. 28 (2019) 8. 